\title{
13 Trans-regional optics and queer affiliations in the work of Jonas Carpignano
}

\author{
Derek Duncan
}

Queer has never been just about sex. Eve Sedgwick made the point that queer's task was 'to do a new kind of justice to the fractal intricacies of language, skin, migration, state' (Sedgwick 1993: 8), and indeed, since its forceful emergence as a modality of identification and practice of critical communication, queer has been operating across multiple axes of marginality and difference. What queer's diverse positionalities perhaps share, even if unequally experienced, is a dissonance and dissidence in relation to the entitlements of national citizenship, whether these entitlements be access to healthcare, education, residence, or other forms of social and cultural security. As Martin F. Manalansan IV states, "Where are you from?” is a question that is posed to the foreigner, the non-citizen, and the queer' (Manalansan IV 2014: 103). The agonistic contest over citizenship is currently being publicly acted out in debates around two modes of human mobility which call into question conventional configurations of identity, practice, and settlement that queer as a sociocultural hermeneutic has worked to destabilise. While the prefix 'trans' applied to both gender and nation has prompted new understandings and practices of being and belonging, it has simultaneously led to the aggressive reformulation of normative strictures of expulsion and abjection because of the very pressure applied by mobile subjects to preexisting temporal and spatial arrangements.

Emma Bond incisively notes that both iterations of 'trans' are to do with 'corporeal geography' and invite 'a certain flexibility in attitudes towards (self)perception and relationality' (Bond 2018: 76). She picks up on transgender theorist Susan Stryker's idea of 'cross-cutting' to affirm the inevitably multiple, varied, and potentially antagonistic articulations of embodied subjectivity. Two almost identically titled essays reflect further on this lexical association to interrogate modalities of 'trans' mobility in ways echoing Bond's emphasis on perception and relationality. Song Hwee Lim's 'Is the trans- in transnational the trans- in transgender?' (Lim 2007), and Jessica Berman's 'Is the Trans in Transnational the Trans in Transgender?' (Berman 2017) investigate the overlaps between the term's deployment as a critical category or heuristic tool rather than social descriptor. Lim's essay anticipates Berman's assertion about 'the potential value of deploying "trans" as 
a critical practice across domains of nationality and gender, and of using it as a key critical optic within new modes of comparative, global, or planetary literary study' (Berman 2017: 236). A strand of Queer Studies has for some time now advanced an 'optic' which brings into critical alignment the discontents of national belonging and the creative imaginings of other cartographies. Gayatri Gopinath's recent work on visual culture and queer curatorial practice revises the too static national/transitional divide by arguing for 'alternative understandings of time, space, and relationality' brokered at both supra- and sub-national levels. She looks instead towards what she calls a 'queer regional imaginary' (my emphasis) to bypass the nation as the sole filter through which connections with other places are made. Like Berman, she posits 'queerness as an optic and reading practice that brings alternative modes of affiliation and relationality into focus' (Gopinath 2018: 10). Their common queer aspiration to reframe the visual field reprises Bond's commitment to apprehending 'shifting gender embodiments through the lens of cultural and linguistic translation and migration movements' (Bond 2018: 21; my emphasis). The kinetic malleability of 'transembodiment' productively works against received formulations of identity, agency, knowledge, and habitation.

The 'queer' and 'trans' optics or lenses of Bond, Berman, Gopinath, and Lim provide the initial methodological coordinates for an analysis of the groundbreaking work of Italian filmmaker Jonas Carpignano. ${ }^{1}$ His two feature films to date are set in the southern Italian region of Calabria and engage aspects of recent migration to Italy in dialogue with other forms of social marginality. Mediterranea (2015, Italy/France/USA) focuses on newly arrived black African migrants and their exploitation in the agricultural labour market, while A Ciambra (2017, Italy/Brazil/France/Germany/ Sweden/USA) centres on Calabria's almost equally marginal Romani community and its life on the edge of the state and formal economy. ${ }^{2}$ Far from being 'regional' in a parochial sense, his two multiethnic and multilingual films define an optic able to apprehend shifting non-national configurations of space, time, and embodied practices of relationality. Just as 'queer' and 'trans' refuse to alight on any single fixed object, 'region' needs to remain a mobile, open signifier. ${ }^{3}$

Before looking at Carpignano's work, it is worth noting that, as Áine O'Healy states, he straddles and confounds any clear-cut categorisation of national belonging (O'Healy 2018: 218). He was raised in New York by his Barbadian mother and Italian father, but also lived for significant periods in Rome. His paternal grandfather worked in film production, introducing Carpignano to Italian cinema at an early age. Since 2010 he has been resident in Gioia Tauro, a small town in Calabria, and is artistic director of its Film Festival dedicated to emerging talent, which he helped set up in 2016. His first two features premiered at the Cannes Film Festival, and while Mediterranea did not secure general release in Italy, it has been distributed widely and celebrated on the international art house circuit. His follow-up 
A Ciambra, produced by Martin Scorsese, was Italy's nomination for Best Foreign Language Film at the Academy Awards in 2017, and Carpignano himself was named best director at Italy's David di Donatello Awards the following year.

A Ciambra's Oscar nomination followed that of Gianfranco Rosi's Fuocoammare/Fire at Sea (2016, Italy/France) the previous year, and it underlines Italian cinema's ongoing, albeit contested, engagement with mobility and multicultural diversity. Yet it has been suggested that Carpignano's work breaks previously dominant paradigms of representation. O'Healy makes the bold claim that with Mediterranea, Carpignano 'opens a new space for thinking about the representation of migration in film and media, not only in Italy, but across the world' (O'Healy 2018: 218). Like the later film, it is semi-scripted and shot from the perspective of its mainly non-professional cast who mostly act out events from their own lives. His involvement with the actors is intense, based on months living in close proximity. ${ }^{4}$ Extensive subtitling reflecting the diversity of the actors/characters strains the conventional monolingual and monocultural bias of the national audience. Hand-held camera-work and extremes of natural lighting selfconsciously texture the cinematic image, and ellipsis characterises narrative progression. Yet O'Healy's idea that the film might create a 'new space... across the world' points to the transnational mobility of director's aesthetic practices.

His work sits in a hybrid space between historical-national and contemporary international styles of filmmaking. Jonathan Romney, for example, in his discussion of A Ciambra, refers back to the hey-day of politically committed cinema: 'Italian neorealism is alive and well in the hands of writerdirector Jonas Carpignano - a fairly textbook version of neorealism, at that' (Romney 2018). ${ }^{5}$ Equally, Francesco Boille recognises that 'his film rediscovers the ambitions of neorealism without ever mindlessly imitating them.' With its thematic and stylistic mingling of fiction and documentary, his work also evokes 'international arthouse cinema at its best' (see Boille 2017). Carpignano echoes this tension or dissonance by both inserting himself into a particular tradition of Italian filmmaking and marking a distance from it:

If you think of what Italian cinema has done, the image that people have of Italy right now is very much attributed to what Rossellini said Italy was after the war, so the national image is very much constructed through cinema. If cinema is really going to give an accurate portrait of a nation, I think it's important to show what is happening to new black Italians or Romany Italians and show that there is a richer and more complex social fabric than Italian cinema has put forth this past century.

(Shia 2018)

He acknowledges that his own biracial heritage may have drawn him to this subject matter but insists that moving beyond Italian cinema's 'traditional, 
white Italian story' was the primary impetus behind his filmmaking. Carpignano's project then might be read as compensatory, filling a gap in Italian cinema's national narrative. Yet there are more interesting, and indeed queerer, ways to approach his revisionary aesthetic. Tavia Nyong'o coins the concept of 'afro-fabulation' to theorise the work of queer black performance artists whose interventions deliberately trouble narratives of black oppression or invisibility. 'Afro-fabulation' involves telling the world otherwise, bringing together what Nyong'o calls the 'incompossible' - people and things that the real world disallows (see Nyong'o 2019). While there is political purpose in referring to Carpignano and his work as 'Italian', it also risks erasing alternative trans-collocations. For instance, before moving to Calabria, Carpignano worked as assistant to Spike Lee on Miracle at St. Anna (2008, Italy/USA), about four African-American GIs in Italy during the Second World War as part of the racially segregated 92nd Infantry Division. This experience points to another aesthetic and historical dimension of Carpignano's not-quite-Italian cinematographic practice. Aligning it with Nyong'o's queer black genealogy offers another axis of intelligibility or optic of cultural translation.

The first section of Mediterranea tracks the hazardous journey of two migrants, Ayiva (Koudous Seihon) and his friend Abas (Alassane Sy), across the desert through Algeria and Libya, before they undertake a precarious sea-crossing with the inexperienced Ayiva at the helm of the small ramshackle vessel. ${ }^{6}$ Arrested and then released by the authorities in Italy, their only option for immediate survival is very badly paid seasonal agricultural work harvesting citrus fruit in Calabria. Ayiva and Abas are neither faceless nor anonymous. Their well-delineated and differentiated characterisation and back-stories prise migrant representation away from the impersonality of both statistical data and the humanitarian gaze (see Browne 2015).

Abas resents their exploitation in the labour market and calls the more compliant Ayiva a 'whore'. Their sense of relationality is very different. Abas sexualises Europe through the heteronormative pornotopia of the internet, while Ayiva develops a friendship with Rocco, his employer, and particularly with Marta, his young daughter. In the film's final section, Carpignano recreates the riots that took place in the Calabrian town of Rosarno in January 2010 , when the black community rose up in protest against the multiple forms of violence to which they were subject. ${ }^{7}$ In the wake of the violence, Ayiva seems to want to return home, yet the sight of his daughter's delight at the MP3 player he sent her causes him to weep and he interrupts their Skype call to hide his tears. The film offers no resolution and the final scene sees him helping out at Marta's birthday party, suggesting he might, in fact, stay on.

O'Healy's extended analysis of the film brings out effectively the startling originality of Carpignano's representation of migrants in Italy through the expansion of its geopolitical coordinates, the emphasis on the migrants' subjective experience, and their defiant resilience in the face of exploitation 
(O'Healy 2018: 218-25). As she also points out, Mediterranea makes the migrant visible as a global or supranational agent. The film's multiple languages push it beyond the limits of national cinema, and Ayiva's ability to operate translingually positions him as an urbane, cosmopolitan subject. Marta's reminder to her grandmother that Ayiva can understand them perfectly as long as they speak Italian and not dialect suggests the limits of their mother tongue. The extensive use of technology and social media to participate in a transnational network of cultural exchange and communication complicates separation on the grounds of national culture and confounds the familiar projection of backwardness onto the non-national citizen. Ayiva Skypes his sister and daughter in Burkina Faso, and the comfortable interior from where they speak contrasts with the bleakness of Ayiva's living conditions in Italy, so inverting any residual assumptions of modernity as a Western property. Popular music has a functional role in this transnational network, and the film features both contemporary dance tracks and more dated Italian songs from artists such as American-born Heather Parisi and the Roman Edoardo Vianello. Ayiva's ringtone is sampled from Rihanna and Calvin Harris's 'We found love', his daughter's favourite track on her new MP3 player. Rihanna's endlessly reiterated invocation of a 'hopeless place' offers a neat metaphor for the desolate orchards of Calabria, yet more compelling is the work the track does in creating an alternative transnational and wholly unpredictable cartography linking Calabria with Barbados (Rihanna), Scotland (Calvin Harris), and Burkina Faso (Seihon). ${ }^{8}$

As noted, the concluding scene sees Ayiva helping out at Marta's party. The intermittently benevolent Rocco invites him into the house for a celebratory drink as the party erupts joyously to the strains of the Italian trio Ricchi e Poveri's anthemic 'Sarà perché ti amo', an old-fashioned pop song even when it premiered at the Sanremo Song Festival, the enormously popular national televisual music event, in 1981. ${ }^{9}$ Ricchi e Poveri (whose career has lasted more than fifty years) unite the nation timelessly, first through anachronism and then through nostalgia for that anachronism. Ayiva's position here in relation to the nation's temporality is uncertain. Shot from his point of the view on the threshold of Rocco's family home, the image blurs, and only the music is heard in a scene where time and space become radically imprecise and ill-defined. Rocco's belated gesture of hospitality grates with his earlier refusal to help Ayiva gain the work permit that would have allowed his daughter to join him in Italy. Rocco glosses his reluctance with an anecdote about his emigrant grandfather and his heroic struggle to survive in the US relying on the support of his compatriots rather than burdening the host nation. Reminding the spectator of Calabria's own migrant past, this lesson in the constitutive limits of nationally defined kinship disturbs the clarity of Ayiva's optic in the final scene, leaving only the sonic imprint of the poly-temporal Italian pop classic.

Pio, the Romani adolescent who features in Mediterranea as a relatively minor, yet memorably charismatic, figure, is the main protagonist of $A$ 
Ciambra's fragmented coming-of-age narrative. His passage to adulthood is brokered through the fraught negotiation of relationships with his extended family, the black African community, and a group of local criminals referred to as the 'Italians'. All three groups live at the margins of the state and its bureaucracies, their antagonistic relationships fused with self-interest. ${ }^{10}$ Their fraught dependency evokes the 'entangled and angular socialities generated by fabulation' identified by Nyong'o (Nyong'o 2019: 6). The film is prefaced by a pastoral scene set in an unidentified landscape and shot in a muted blue palette. A young man strokes a saddleless horse before drinking water from a fast-flowing stream into which he squeezes some fresh lemon juice. His tin cup, the canvas-covered caravans, and open fire in the background connote pastness. The scene marks a temporal and visual contrast with what follows: first, overexposed footage of Pio in close-up, then a series of fast cuts conveying the chaos of an overcrowded apartment. The subtitling of the Calabrian dialogue intensifies the national spectator's disorientation. It becomes apparent that the young man in the previous scene is Pio's now very elderly and infirm grandfather for whom Pio prepares a glass of lemon and water taken from a tap. The opening scenes introduce what is a very extended family. While Rocco and his wife's one-child-and-one-grandparent arrangement is crystal clear in its predictable heteronormativity and generational separation, Pio's is less fathomable. The large number of children is at odds with the stereotypically small contemporary Italian household, and while Rocco's family very much identifies with the domestic interior, Pio and his family are characteristically seen outside their decaying apartment block in a landscape strewn with waste.

The film takes its name from 'La Ciambra', the estate on the outskirts of Gioia Tauro where the large local Romani community is housed. ${ }^{11}$ The housing blocks are often seen in aerial long-shot or in medium close-up, allowing the spectator little sense of place. Similarly, when Pio leaves the estate, he is shot in anonymous, desolate locations. Intergenerational differences blur, and the spectator struggles to map patterns of kinship with any accuracy. The family operates in a cash economy through various forms of petty crime rather than earning a living through waged work. Pio's father is arrested for electricity theft, prompting Pio to scale up his own activities to provide for the family until a clash with the local 'Italian' criminals leads to his temporary expulsion from home. Unable to read and write, Pio trades technology as a commodity on the black market. As an adolescent, he is caught between playing with the younger children and trying to become more involved in the activities of the adult family members. Boille reflects on Pio's anachronism: 'you don't get characters like Pio anymore in Italian cinema' (Boille 2017). He smokes and drinks (although he distances himself from drugs), yet the on-screen presence of cigarette-smoking toddlers suggests that Pio's apparent defiance of conventional expectations about ageappropriate behaviour is not simply a character trait but symptomatic of a broader expression of asynchronous, cultural dissonance. 
The Amato family as a collective is queer when it comes to time. For Halberstam, 'queer time' reveals the degree to which normativity depends on selective investment in the schedules of 'reproductive temporality', 'longevity', and other measures which afford value to middle-class lives, suggesting 'queerness as an outcome of strange temporalities, imaginative life schedules and eccentric economic practices' (Halberstam 2005: 11). Elizabeth Freeman extends this intersection of class and temporality through her concept of 'chrononormativity', an analysis of embodied responses to heteronormative life patterns and waged labour that also indexes class-based practices of selforganisation and corporeal disposition: 'Bodies ... come to matter through kinetic and sensory forms of normativity' (Freeman 2010: 172). Wheeling and dealing in stolen goods already places Pio on the margins of the formal state economy. Out and about in the middle of the night, he is illiterate and doesn't attend school. He dissents from the national, class-based 'dispositif' through all that he does, becoming one of Freeman's 'denizens of times out of joint' (Freeman 2010: 19), 'living aslant' (Freeman 2010: xv) by following the beat of alternative temporal rhythms and therefore living 'out of synch with state-sponsored narratives of belonging and becoming' (Freeman 2010: $\mathrm{xv})$. 'Living aslant' is time's queer embodiment.

It is difficult to measure time in the film itself as the narrative's lack of progression or development is at odds with conventional mechanisms of plotting. David Ehrlich is unsympathetic to this, saying that the 'story is as messy as the experience of growing up in Gioia Tauro' (Ehrlich (2017). Boille writes approvingly about the 'floating' or 'suspension' of time in the film (Boille 2017), while Romney feels that A Ciambra'does sometimes lack shape. The course of events feels baggy and repetitive' (Romney 2018). The recurrent sight of a photograph of the younger grandfather throughout the film anticipates a non-narrativised relationship with the past while creating a marginal disturbance of vision, a kind of jump-cut in the filmic texture. Temporal alteration is most palpable in the scenes where the grandfather appears to Pio as a ghost, once in immediate anticipation of his death, and once after Pio's expulsion from home. Carpignano reflects that he wanted his choice to express the past's affective, hallucinatory grip on Pio:

I [Carpignano] tried to conjugate the abstraction of an imagined past with the realism of the film. The barely perceptible slow motion and the magical feeling of those scenes are an obvious departure from the rest of the film, but at the same time they are shot within the 'rules' of the visual language we established for the whole film.

Ghosts have little place in the world of Italian neorealism, yet they manifest strongly in queer thinking (see Freccero 2006). For Carpignano, as for Freeman, they evoke both history and the call for reparation. Drawing on Derrida's Specters of Marx (1993), Freeman affirms its contribution to queer theory's anti-chrononormative impulse towards the creation of new 
relations and forms of justice. Ghosts stand outside history and insist on the presence of the past in the present. Following Avery Gordon, she asserts that they incarnate not only the dead but also 'repressed events and social formations' (Freeman 2010: 98). This ghost, sitting aslant life and death, has assumed the grandfather's younger form and is accompanied by the same horse. The theatricality of their appearance announces the persistence of a troubling past whose effects reverberate across the remainder of the narrative. In Nyong'o's terms, they represent 'the persistent re-appearance of what was never meant to appear, but was instead meant to be kept outside or below representation' (Nyong'o 2019: 6). They form part of the texture of the film's queerness.

After the grandfather's funeral, Pio's tries to persuade Cosimo, his reluctant older brother, to go into business. ${ }^{12}$ The sound-track to this conversation is Tony Colombo's 'Nun fazzu pi tia' (I don't do/I am not good enough for you). ${ }^{13}$ The Sicilian singer is a successful exponent of 'new-melodic' music, a contemporary phenomenon styling itself on traditional 'canzone napoletana'. From the nineteenth century onwards, this dialect tradition enjoyed significant transnational success, and successive remediations by classically trained vocalists have blurred its popular origins. Sung in the dialect of Palermo (modified to render it more intelligible to a national audience), 'Nun fazzu pi tia', an avowedly anachronistic, homosocial ballad about a young man separated from the girl he loves because of her father's disapproval, sits 'aslant' geographical, cultural, and temporal boundaries. Colombo himself

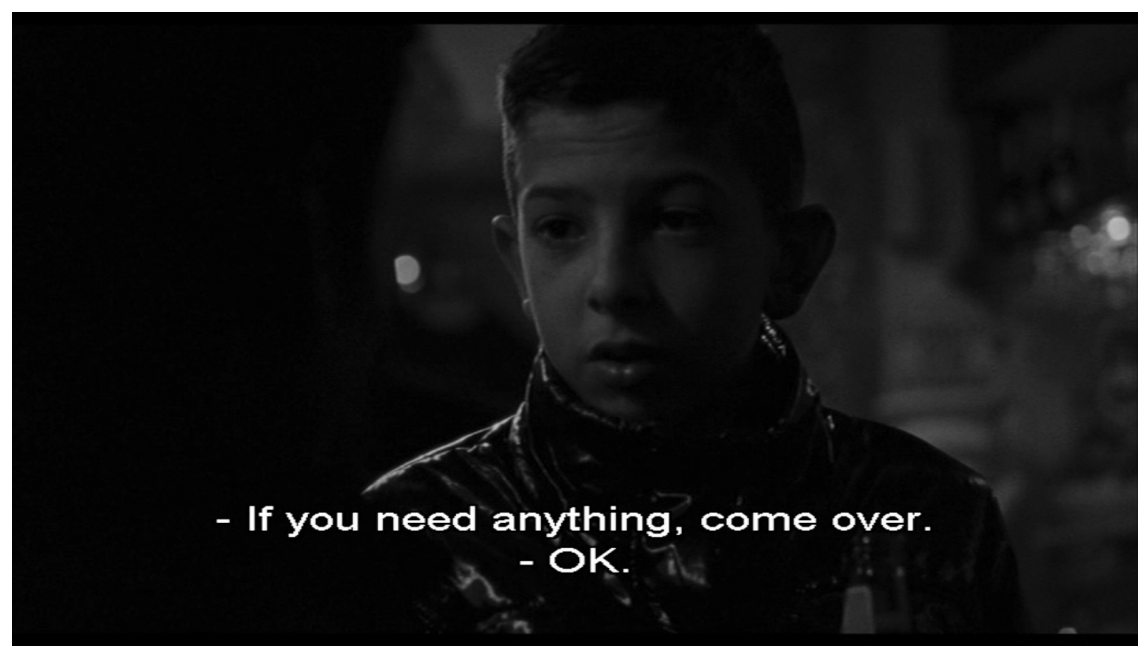

Figure 13.1 Pio (Pio Amato) reaches out to Aviya (Koudous Seihon) in Mediterranea (2015)

Source: Mediterranea (2015), directed by Jonas Carpignano (C) DCM, Audax Films, Blu Grotto, Court 13 Pictures, Good Films, and Studiocanal (UK) (2016). 
has been described as a 'man out of time' (Mariarca 2018) because of his readiness to display emotion and vulnerability. In this sense, Pio's alternative affective alliance with Ayiva is also queerly out of time, at odds with both his family's unselfconsciously expressed racism and their admonitions not to go outside the community. In the words of the song, Ayiva 'doesn't do' for Pio.

While in Mediterranea Pio had been in a position to help out the newly arrived Ayiva, things have clearly moved on, and in A Ciambra, Ayiva assumes more the role of protective, older brother to the now vulnerable Pio. ${ }^{14}$ His friendship with Ayiva is an instance of what Halberstam calls 'alternative methods of alliance' (Halberstam 2005: 1) and contributes to Pio's framing as an almost archetypally queer trans-regional subject. Having managed to supply a group of Africans with a large-screen television, Pio quickly makes friends learning an alternative mode of socialisation and effecting an 'adjustment' (Halberstam 2005: 6) in how he experiences and moves across cultural spaces. In an overview of recent films set in Calabria, Felice Cimatti refers to their relationship as 'monstrous', an adjective he also applies to the triangulation of communities (Romani, migrant, criminal), or 'angular socialities', in which they live. Their 'monstrosity' relates to the baroque novelty of their existence which, like the deformed language or 'pidgin' they speak, does not see the nation (past or present) as a meaningful reference point (Cimatti and Dempsey 2018). It depends, too, on the scandal of race, reminiscent of the outrage documented in Countee Cullen's short poem 'Tableau' (1925) glossed by Sara Ahmed. The poem presents a vignette of two queer boys, a 'black body and a white body', out walking together, their defiant yet carefree public appearance eliciting disapproval from both communities. Their actions flaunt the scandal of their improper pairing: 'It is', Ahmed reflects, 'the proximity of these bodies that produces a queer effect' (Ahmed 2006: 169). Seen in this light, their relationship creates a queer proximity between Carpignano and the Harlem Renaissance. Cullen had also married Yolande, the only daughter of the black intellectual W.E.B. Du Bois, all three men spending formative parts of their lives in Europe. ${ }^{15}$

This queerness of Pio and Ayiva's spatial transgression proves too much for Cosimo, who forces his brother to betray his friend to secure his reintegration into the family. Pio lures Ayiva away from the lock-up where he stores the goods he sells on the black market. He deliberately crashes his bike, falling off and wounding his head before calling Ayiva to come and pick him up. Shot almost exclusively in barely lit close-up, the camera lingers on Pio's bloodied forehead and the tears he sheds over his betrayal. The 'proximity of these bodies' exudes an almost unbearable poignancy and tenderness as Ayiva embraces Pio. On the back of the motorbike, Pio cleaves to his friend, their hands, black on white, firmly clasped, temporarily suspending Pio's normative gesture of familial reconciliation. In the meantime, Cosimo has ransacked the lock-up.

The extirpation of Pio's queerness takes a more obviously sexualised turn when his brother treats him to a visit to a local prostitute to initiate him 


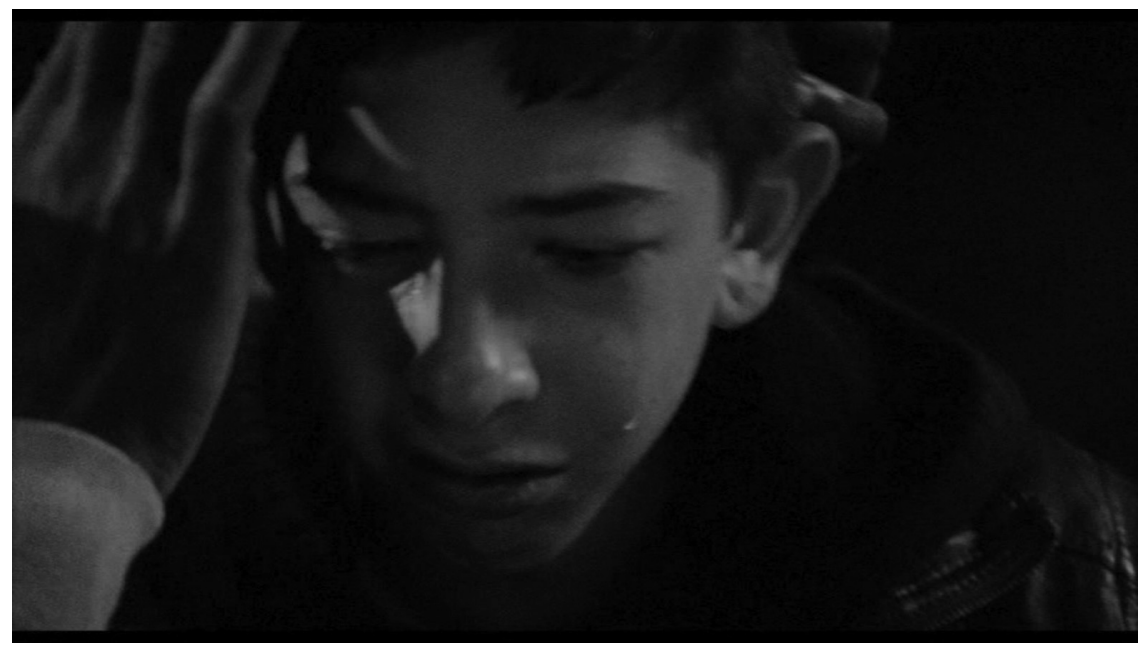

Figure 13.2 Aviya's hand, Pio's tears, in A Ciambra (2017)

Source: A Ciambra (2017), directed by Jonas Carpignano (C) Stayblack, RT Features, Rai Cinema, Sikelia Productions, and Academy Two (Italy) (2017).

into male adulthood. The camera dwells on Pio's face as the white prostitute performs oral sex. The film's subsequent and concluding sequence sees Pio welcomed into the space of adult men and leaving behind the women and children, no longer stuck in the marginal, queer space in-between. While this experience symbolically marks Pio's entry into normative adult masculinity, it also recalls a very brief scene in Mediterranea when Ayiva sees one of his black female friends performing oral sex on a white man. A relaxed social evening had been interrupted by the arrival of white Italian criminals who force the women to leave. Visibly uncomfortable, Ayiva and some of the other men decide to go. Their disempowerment is confirmed by his fleeting glimpse of his friend. Their common subjection to the prejudicial logics of race and citizenship is palpable through the interstices of this queer optic.

Queer is also always about sex. Both of these scenes of oral penetration bespeak subjugation rather than pleasure and arguably make manifest the erotic failure as well as the price of heteronormativity. Freeman writes about the damage and pain inflicted on the queer body, and the unlikely emergence of 'queer social contours, a wounded morphology of the social following a wounded morphology of the individual' (Freeman 2010: 12). The blood from Pio's self-inflicted wound articulates a 'morphology of the social' that rehearses the systemic violence inflicted onto all the marginal, migrant, and resolutely queer subjects of Carpignano's film. He doesn't cry, however, because his head hurts. His tears haunt by virtue of their own queer temporality emanating from an affective past, and mourning what 
has become an unrealisable future. ${ }^{16}$ His tears, rehearsing those of Ayiva in the earlier film, reaffirm their affective and asynchronous affinity. Pio, like Ayiva, is a denizen out of time, and the film, as a coming-of-age narrative, records his attempts to become an adult male by shunning the scandal of race and returning to a mode of fabulation driven by the segregation of sexuality and race.

Carpignano's commitment to racial and transnational diversification positions him as what might be called a trans-regional queer theorist, whose cinematic optic aligns subjects distant from normative configurations of social subjectivity and their entitlements. This commitment may be regarded as a contribution to the 'new kind of justice' intimated by Sedgwick. To reprise Stryker, his aesthetic practice of 'cutting across' accepted designations of spatial and temporal border reaffirms queer as a mobile critical category in the terms and spirit intimated by Carla Freccero:

Queer, to me [Freccero], is the name of a certain unsettling in relation to heteronormativity. It can be thought of as, and is akin to, the 'trace' in the field of sexuality. Thus créolité, hybridity, mestizaje, métissage, spectrality, the trace, and the uncanny all find themselves in certain ways allied with queer as terms that do the work of differance in relation to the identitarian inflections they carry, though each speaks to different discursive domains and targets specifically and differently inflected binaristic identitarian normativities.

(Freccero 2011: 17)

Freccero's vertiginous menu does not list 'trans' as an option. Yet all the options she does propose contain the 'trace' of a material, often linguistically marked, embodied encounter of crossing redolent of Carpignano himself as a black, American Italian aslant diverse genealogies. Mediterranea's inclusion of gay icon Rihanna's 'S\&M' offers a 'trace' or even a promise that other forms of sociability or kinship are possible. Contrapuntally, the year of the film's release, 2015, saw the opening in Milan of Sarà perché ti amo, a musical drawing extensively on Ricchi e Poveri's most famous numbers, referred to by one reviewer, in a gesture to Gramsci, as 'ultranational popular music' (see Naso 2015). The twist, however, is the remediation of the title-track in a gay subplot which seemed to appeal to the audience, but came as a terrible shock to the songwriter who had imagined his lyrics to be resolutely straight. The inversion confirms the transformation of Rocco's Calabrian living room into a site of non-normative, asynchronous, musical pleasure queering the transparencies of nationally defined space and disturbing its optics. Seriously aslant.

\section{Notes}

1 For Berman "the term "trans" bears affinities with the ways that theorists deploy "queer" as an attitude, activity, or process rather than a substantive identity or 
specific sexuality' (Berman 2017: 239). In a pointed aside on his engagement with both Trans and Queer Studies, Nyong'o remarks that he 'does not seek to conflate them or force their complementarity' (Nyong'o 2019: 14). My own argument proceeds with these distinctions in mind.

2 Clough Marinaro (2014) provides a full account of the ways in which Italy's Romani communities have been targeted in the campaign of hostility to migrants. Over the last fifteen or so years, Romani camps have been the focus of ongoing violent incursions by supporters of the far-right. From 2018, Matteo Salvini, the Northern League politician and now former Deputy Prime Minister, has been vocal in condemning the presence of Romani people on Italian territory and supported the police clearing of the long-established River Roma camp in the face of an EU directive against the clearing (see Tondo 2019b). See Hope (2016) for a wide-ranging discussion of Roma in recent Italian cinema.

3 The advantage of the term 'trans-regional' is that it remains ambiguous, playing with different scales of interconnectedness and entanglement from the relatively local to the continental. It always, however, sidesteps the nation as the determining unit of geopolitical significance.

4 In interviews, Carpignano has talked extensively about the closeness of his relationship with Koudous Seihon and Pio Amato, the non-professional stars of his two films. Their friendship allowed him access to the respective communities whose experiences form the core of each narrative.

5 Italian neorealism is associated primarily, albeit not exclusively, with Rome as a metonym for the nation itself. Angelo Restivo comments on Italian cinema's complex temporal layering expressed throughout the postwar period. See Restivo (2002). His argument resonates with much of what I say, although I argue that Carpignano's work does not retain the nation as a structural determinant.

6 Carpignano has talked about the trauma the actors experienced reenacting the scenes of the crossing (see Rapold 2015). Alassane Sy was the only professional actor in the film. Born in Mauretania, as a child he fled to Senegal with his family. He later established himself as an actor and model working in France, the UK, and US. He currently edits Nataal, the African-focused digital/print culture magazine.

7 The riots, in fact, inspired Carpignano's decision to relocate to Calabria. Koudous Seihon also took part in an extensive report on the events in Rosarno drafted by a group of NGOs active in Calabria. The riots were the subject of Il Sangue Verde/Green Blood (2010, Italy), a documentary directed by Andrea Segre. The film includes interviews with a number of those involved and makes an explicit comparison between present-day exploitation of migrants and the historical exploitation of agricultural workers.

8 In the press notes issued for the release of A Ciambra, Carpignano talks about his love of popular music and its capacity to bring people from different backgrounds together. I would want to stress, however, that, like all cultural products, music is transformed as it travels. See Carpignano (2017).

9 Countless versions of the track are available on YouTube. For more information on Ricchi e Poveri, see their website https://ricchiepoveri.com/it/.

10 Carpignano plans to complete the sequence of films with the provisionally titled A Chiara, set in the town's 'Italian' community. Release is scheduled for 2020.

11 Carpignano's representation of the community, its way of life, and the conditions in which it lives has been criticised as too reliant on stereotypes of criminality. See Stasolla (2017).

12 Cosimo is played by Damiano Amato, his real-life twin. The brothers are named after Saints Cosma and Damiano, traditionally venerated by Calabria's Romani community and celebrated by them in a series of ceremonies held over three days every September in the town of Riace. Riace has in recent years become well known for its attempts to counter depopulation by attracting migrants to it. 
Domenico Lucano, the town's mayor who led this project, has been charged with a number of offences involving the use of public funds and colluding in illegal migration.

13 The video accompanying the track offers a startlingly literal, yet brazenly unreal, rendition of the content and tone of the lyrics: www.youtube.com/ watch? $v=H R S 3 n u t b E N c$.

14 In a general reflection on the burden placed on children in Italian migration cinema, Danielle Hipkins asks: 'What impossible futurity does Italian cinema's emphasis on the "Italian” white child fantasize?' (Hipkins 2014: 24). In my reading, Carpignano revises the conventions of that heteronormative logic through the temporal (dis)locatedness of the adolescent Pio.

15 Jeremy Braddock effectively elucidates the latent queerness of Cullen's work. In terms of Carpignano's own aesthetic practice, we note Braddock's reference to James Snead's work on repetition as an expressive strategy in black culture: 'the virtue of repetition consists in the way in which it enables a return or a restaging of an unavailable or repressed history' (Braddock 2002: 1265). This is a helpful way of thinking about ghosts in A Ciambra, and also Carpignano's comments on the triptych as a non-narrative assemblage. See Fierro and Fierro (2018).

16 Pio's tears can be read as a performative instance of 'heterosexual melancholy' which, according to Judith Butler, is 'culturally instituted and maintained as the price of stable, gender identities related through oppositional desires' (Butler 1990: 95). 